\title{
Development of hexagonal maze procedure for evaluating memory in rat
}

\author{
RUI-XIN XU ${ }^{1}$, NIKOLAY GRIGORYEV ${ }^{2}$, TING-LI LI ${ }^{1}$, HONG-SHENG BIAN $^{1}$, RU ZHANG ${ }^{1}$ and XIAO-YAN LIU ${ }^{1}$ \\ ${ }^{1}$ Department of Pharmaceutical Sciences, Heilongjiang University of Chinese Medicine, Harbin 150040, P.R. China; \\ ${ }^{2}$ Department of Physiology, Amur State Medical Academy, Blagoveschensk 675000, Russia
}

Received August 9, 2012; Accepted September 26, 2012

DOI: $10.3892 /$ br.2012.16

\begin{abstract}
Memory is known as a series of behavioral changes caused by an experience, while learning is a process for acquiring memory. In the present study, we suggested a new method (hexagonal maze) to evaluate the learning and memory of rats. For preliminary validation, the authors used the maze to carry out two classical experiments. At first, the performance of rats of various ages was observed in the maze. Additionally, after establishing the rapid eye movement (REM) sleep deprivation model using the modified multiple platform method (MMPM), the authors also utilized a new experimental device to analyze learning and memory responses to REM sleep deprivation in rats. Behavior of the rats in the maze was recorded by a video recorder and was then quantified. According to the behavioral characteristics, rats of various ages showed differences in memory. Middle-aged male rats exhibited a higher level compared to the young $(\mathrm{P}<0.05)$ and the old group $(\mathrm{P}<0.01)$. The results also indicated that the ability of learning and memory showed a significant decrease $(\mathrm{P}<0.05)$ after $\mathrm{REM}$ sleep deprivation. These findings were consistent with those of several similar studies using one of the adopted procedures (Morris water maze, radial arm maze and the Y-maze). Based on the above-mentioned preliminary experiments, the introduction of a hexagonal maze may provide an applicable method for analyzing learning and memory of rat.
\end{abstract}

\section{Introduction}

Memory is one of the most important fundamental neurological activities, which in fact is not a single function but a cooperation of mental abilities that depend on different

Correspondence to: Dr Ting-Li Li, Department of Pharmaceutical Sciences, Heilongjiang University of Chinese Medicine, 24 Heping Road, Harbin 150040, P.R. China

E-mail: xrxgf@yahoo.com.cn

Key words: hexagonal maze, learning and memory, rapid eye movement sleep deprivation, cognitive behavior systems within the brain (1-3). Memory is known as a series of behavioral changes caused by an experience, while learning is a process for acquiring memory. Several diseases, such as Parkinson disease, depression, senile dementia or brain trauma, are associated with learning and memory decline, especially among the elderly (4-7). Since learning and memory are crucial in cognitive processes, it has been suggested that humans as well as animals of various ages exhibit different memory and learning abilities $(8,9)$. Age-related changes have been reported for a range of cognitive functions (10). Moreover, sleep is involved in the consolidation of memory traces originating from a number of experimental observations (11). A large number of studies offer substantive evidence supporting this so-called sleep-dependent memory processing (12).

Sleep deprivation appears to have wide-ranging effects. Reduced arousal of attention coupled with impaired central processing lead to an overall decline in cognitive functioning (13). Sleep deprivation studies in animals, mostly laboratory rats or mice, have mainly investigated the effect of partial or selective rapid eye movement (REM) sleep deprivation on memory (14). When REM sleep was deprived, rats showed impaired memory and cognition in Morris water maze, radial arm maze and the Y-maze (15-17).

In the present study, the new experimental device, the hexagonal maze was investigated. The aim of the study was to explore whether or not the new method quantified the extent of learning ability and memory in the rodent model.

\section{Materials and methods}

Experimental animals. The experiments were carried out in compliance with the guidelines for animal care of the Medical Ethics Committee of the Heilongjiang University of Chinese Medicine. Male Wistar rats $(n=50)$ from our colony were used in the study. The subjects were categorized into three age groups: the young (age, 2-3 months; weight, 100-120 g); the middle-aged (age, 6-7 months; weight, 180-220 g) and the old groups (age, 18-24 months; weight, 300-350 g). Groups were housed respectively in a large plastic cage $(86.0 \times 62.0 \times 30 \mathrm{~cm})$ after weaning. Lights were on from 7:00 am to 7:00 pm (light cycle) and off from 7:00 pm to 7:00 am (dark cycle). Room temperature was kept at $20 \pm 2^{\circ} \mathrm{C}$ and animals had access to water and food ad libitum. The experimental manipulations took place at 8:00 am. 


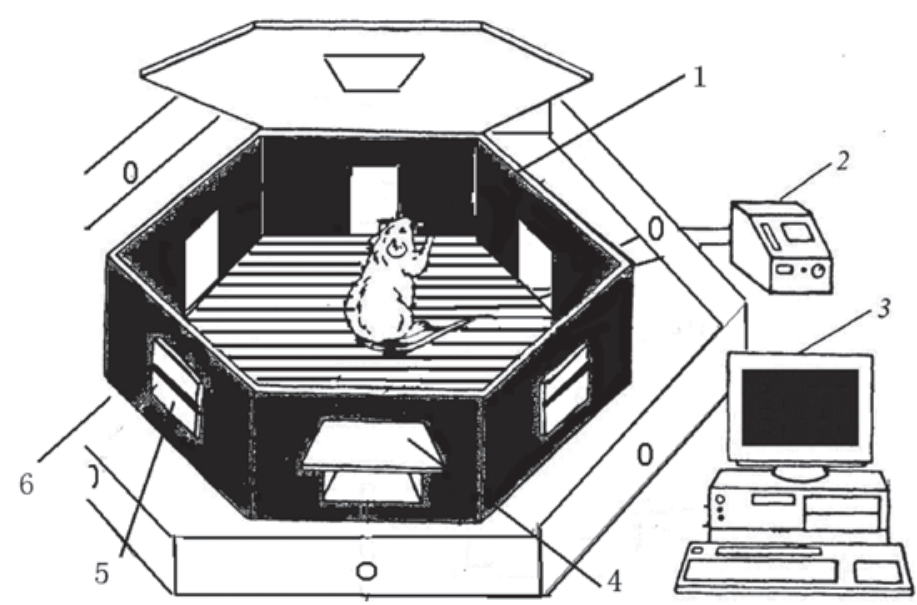

Figure 1. Sructure of hexagonal maze is shown: 1, maze box; 2, electrical stimulator; 3, computer; 4, unlocked door; 5, locked door; 6, safe district.

Experimental device. The hexagonal maze is mainly made of polymethyl methacrylate plastics (Fig. 1). The maze is regular hexagonal, has six doors (one in each direction), and an entrance on the top of the maze through which the rat was placed in the maze. The floor is made of electrical grilles. Additionally, there was a large hexagonal area outside the maze without electrical grilles on the floor, known as safe district. A ring was fixed on the maze. Three seconds after the ring, the electrical grilles were galvanized $(1 \mathrm{~mA})$ for $1 \mathrm{sec}$, and this was repeated every $20 \mathrm{sec}$ until the rat found the door and reached the safe district. Finding time (FT), finding frequency (FF) and cognitive rate (CR) were recorded by a video recorder.

Trial in hexagonal maze. The rats were caressed for 7 days prior to the trial, 1-2 min each day to reduce the indifferent stimulus. The trial included four consecutive days of contents. The anterior three days were learning process, with behavior of the rat being observed on the last day. On the first day, the six doors of the maze were unlocked. A rat was then placed into the maze through the top. The trial ended as soon as the rat found a door to reach the safe district without any stimulus. On the second day, the rat was placed into the maze, with the ring used as a signal. Three seconds after the ring, the electrical grilles were galvanized ( $1 \mathrm{~mA})$ for $1 \mathrm{sec}$ and it was repeated every $20 \mathrm{sec}$ until the rat found a door and reached the safe district. The rat was then put back again into the maze and the program was repeated several times to facilitate an initiative withdrawal reflex. When the rat was placed into the maze, it was eager to find a door to escape to the safe district. On the following day, the rat was placed into the maze, the electrical grilles were galvanized after the ring similar to that on the second day, and the rat reached the safe district through a door. The door was locked and the rat was returned to the maze. The rat was expected to find another door to escape from the maze. The trial was repeated until the rat found all the six doors, signaling the end of the learning process. The trial on the fourth and last day was similar to that of the third day. The difference was that the ring was heard every $24 \mathrm{sec}$, but without electrical current on the grilles. The behavior of the rat was recorded by a video recorder. The maze box, grilles and the safe district were wiped using alcohol after the performance of each rat to avoid the influence of smell on the next rat.
Observation index. FT was determined as the time period between the placement of the rat into the maze and its finding of the door to the safe district. FT reflects the ability of spatial exploration and the efficiency of finishing the task set in rats, while $\mathrm{FF}$ was regarded as the number of doors that a rat found in $1 \mathrm{~min}$. It was calculated using the formula: $\mathrm{FF}=$ the total number of doors that rat finds/FF.

The total number of doors a rat found was the summation of the right and the wrong number of times. Rats selecting the locked doors to pass through were considered to be wrong, while rats selecting unlocked doors to pass through were considered to be right. Of note, the right number of times was always six in the study. Thus, $\mathrm{FF}=6+$ wrong number of times/FF, with FF reflecting the excitability of rats. $\mathrm{CR}=$ (the right/the total number of times) $\times 100 \%$. If the rat did not make an error in the study, the CR was considered to be $100 \%$. CR represented memory, i.e., the cognitive ability of rats.

Performance of rats of various age groups in hexagonal maze. Male Wistar rats $(\mathrm{n}=30)$ were divided into three age groups: the young ( $\mathrm{n}=10$; age, 2-3 months; weight, 100-120 g); the middle-aged ( $\mathrm{n}=10$; age, 6-7 months; weight, 180-220 g) and the old groups ( $\mathrm{n}=10$; age, 18-24 months; weight, 300-350 g). Subsequent to caressing for 7 days, the rats were placed into the maze one by one to initiate the learning process. Behavior of the rats was observed on the last day.

Performance of rats following REM sleep deprivation in a hexagonal maze. Middle-aged male Wistar rats $(\mathrm{n}=20$; age, 6-7 months; weight, 180-220 g) were divided into two groups: the control (wide platforms, $\mathrm{n}=10$ ) and the REM sleep deprivation groups (narrow platforms, $\mathrm{n}=10$ ).

The Modified Multiple Platform Method (MMPM) was used in this experiment. Twelve narrow platforms $(6.3 \mathrm{~cm}$ in diameter, while wide platforms were $12 \mathrm{~cm}$ in diameter) were placed inside a tilled water tank $(90.0 \times 70.0 \times 50.0 \mathrm{~cm})$, made of polymethyl methacrylate plastics. The rods were placed $15 \mathrm{~cm}$ apart from each other. Ten rats were placed on top of the platforms, thus allowing for space to move around. Each group was placed in one tank. The tanks were filled with water and the surface of the water was $1 \mathrm{~cm}$ below the platform. Exposure to the MMPM began at 8:00 am and the animals 

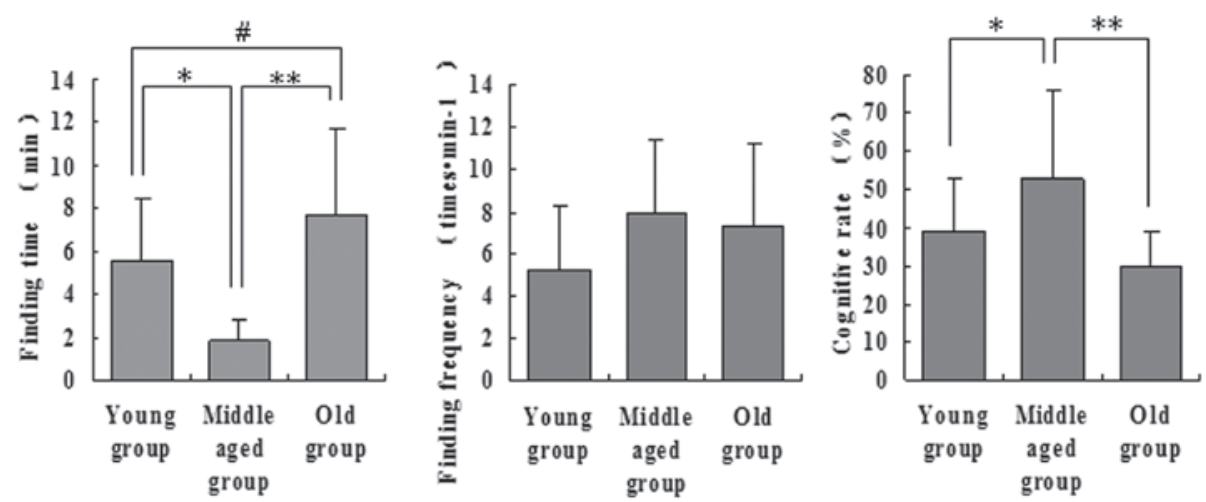

Figure 2. Performance of rats of various age groups in hexagonal maze is shown. Values are representative of the mean \pm standard deviation for 10 rats/group. ${ }^{*} \mathrm{P}<0.05$ compared to the middle-aged group; ${ }^{* *} \mathrm{P}<0.01$ compared to the middle-aged group; ${ }^{*} \mathrm{P}<0.05$ compared to the old age group.
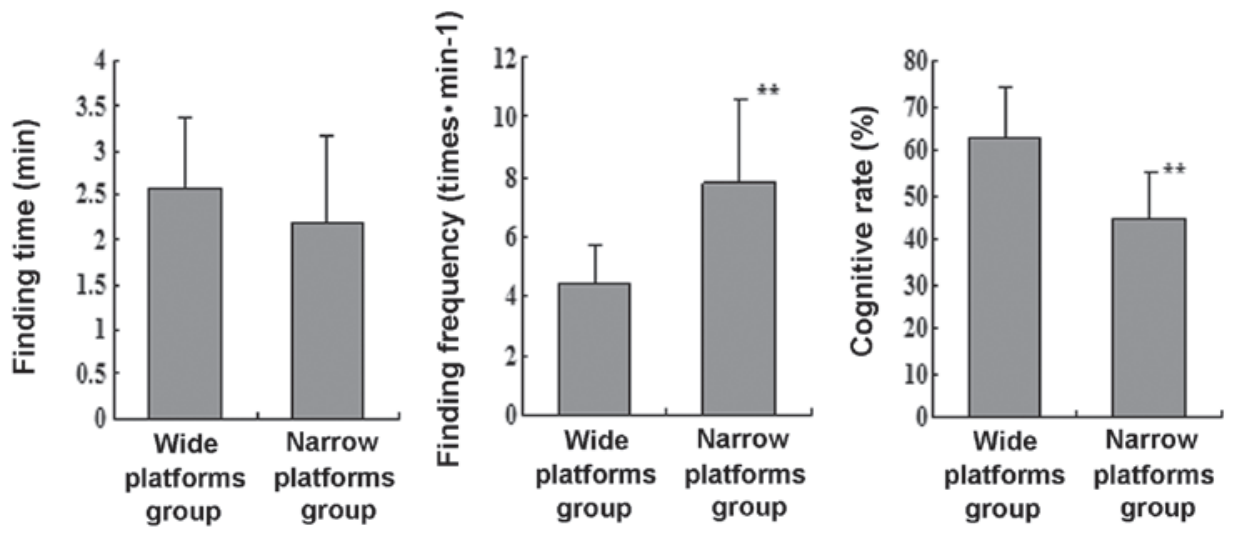

Figure 3. Performance of rats in hexagonal maze after REM sleep deprivation is shown. Values are representative of the mean \pm standard deviation for 10 rats/group. ${ }^{* *} \mathrm{P}<0.01$ compared to the wide platforms group.

remained inside the tanks for $96 \mathrm{~h}$. Throughout the sleep deprivation process, the experimental room was kept at a controlled temperature $\left(20 \pm 2^{\circ} \mathrm{C}\right)$, without a light-dark cycle. Food and water were provided ad libitum by placing chow pellets and water bottles on a grid, made of stainless steel, located on top of the tanks. The water in the tank was changed daily, throughout the manipulation period. Wide platforms were included in an attempt to establish an adequate control group for the REM sleep deprivation environment. The animals on wide platforms were allowed to be recumbent without falling into the water, albeit their tails might have been in the water. Rats were placed into the tank a week prior to the experiments, $1 \mathrm{~h} /$ day, for acclimatization.

This study investigated the effect of sleep deprivation on learning ability and memory in rats. REM sleep was deprived in the process of memory formation, consolidation and reconstruction. The rat was placed into the maze following REM sleep deprivation for $24 \mathrm{~h}$. The first day's program was then applied, while the second day's program was applied subsequent to REM sleep deprivation for $48 \mathrm{~h}$; similarly, the third after $72 \mathrm{~h}$ and the fourth after $96 \mathrm{~h}$. The behavior of the rats was observed on the last day.

Statistical analysis. The total number of animals was 10 rats/group. Each rat was subjected to the program. Learning ability and memory were quantified by the hexagonal maze.
For statistical comparisons, the level of the learning ability and memory were assessed by FT, FF and CR. The findings of FT and FF in the three age groups were compared using analysis of variance (ANOVA) test with Tukey's post hoc for assessing memory consolidation, while the t-test was used for the assessment of memory retrieval in the sleep deprivation experiment. However, the findings of $\mathrm{CR}$ in each group were compared using the Chi-Square test. $\mathrm{P}<0.05$ was considered to indicate a statistically significant difference.

\section{Results}

Performance of rats of various age groups in the hexagonal maze. A significant age effect was associated with the characteristic of FT (Fig. 2). The post-hoc test showed that the time period was longer for the young $(\mathrm{P}<0.05)$ and old age groups $(\mathrm{P}<0.01)$ compared to the middle-aged group. A statistically significant difference was observed between the young and the old age groups $(\mathrm{P}<0.05)$. Although a trend is apparent in the FF, ANOVA did not show any significant effect of age $[\mathrm{F}(2,28)=3.06$, $\mathrm{P}>0.05]$. In the $\mathrm{CR}$, a significant effect of age was observed. Compared to the middle-aged group the cognitive level was lower in the young $(\mathrm{P}<0.05)$ and the old age groups $(\mathrm{P}<0.01)$

Performance of the rats in the hexagonal maze subsequent to REM sleep deprivation. The findings regarding the 
performance of the rats in the hexagonal maze following REM sleep deprivation are shown in Fig. 3. Placement of the animals onto narrow platforms led to the FT being slightly shorter compared to the wide platform group. However, no statistically significant difference was detected between the two groups $(\mathrm{P}>0.05)$. Additionally, the placement of the rats onto narrow platforms resulted in a statistically significant increase of $\mathrm{FF}[\mathrm{t}(18)=3.15, \mathrm{P}<0.01]$ in the hexagonal maze compared to the wide platform group. However, in CR, the wide platform group was still higher compared to the narrow platform group $[\mathrm{t}(18)=2.69, \mathrm{P}<0.05]$ (Fig. 3).

\section{Discussion}

Behavioral approach is crucial in the processes of learning and memory, which quantified changes of learning and memory in animals. Currently, there are several mazes to test the behavior of rats. Among them, Morris water maze (18-20), radial maze (21-23) and the Y-maze (24-26) are relatively commonly used. The hexagonal maze combined with the partial advantages of several mazes quantified the activities of rats and reflected the degree of learning ability as well as memory. Due to the relative experimental characteristics provided by the hexagonal maze, it could reflect the cognitive level of animals particularly and objectively. Since this device was relatively small, the findings would not be affected by physical efficiency decline of the rat. Besides, the method could be combined with neuro-electrophysiological technique to record electrophysiological changes in activities.

Previous studies have shown that age affects the overall performance, and differences due to age were evident $(27,28)$. In this study, the middle-aged group showed a better behavioral performance compared to the old and the young groups in almost all the characteristics. Specifically, it took the middle-aged group significantly less time FT to find the exits. Thus, the middle-aged group exhibited a better ability of spatial exploration and regarding the efficiency of finishing the task, the young group demonstrated a better ability compared to the old group. However, no significance existed in FF, suggesting that rats in each group showed equal excitability. It was notable that the old age group showed deficits of memory and cognitive ability (seen from CR) compared to the young and middle-aged groups, confirming the previous findings $(29,30)$, regarding a number of age-related neurobiological changes that underlie the behavioral impairments. Previous studies have shown that the central cholinergic system was extremely pivotal to learning ability and memory $(31,32)$. Changes in cholinergic function may be a permissive factor for age-related processes that are more directly responsible for cognitive impairments (33).

In the present study, MMPM was used to create a REM sleep deprivation model (34). This method selectively deprives of REM sleep. REM is a stage of sleep characterized by REM and measured by low voltage fast pattern electroencephalogram (EEG). The platform was first used for cats (35) and was later adapted for rats (36). Van Hulzen et al (37), Suchecki and Tufik (38) have improved this method gradually. They took advantage of the atonia that occurred during the phase of sleep. When animals entered the REM phase, they lost postural tone and slipped from the platform into the water and woke. However, it was demonstrated that rats subjected to this procedure exhibited a highly stressful situation in the tank due to social instability (34). Thus, in the present study, each group of rats was raised in the same cage and placed in the same tank when subjected to REM sleep deprivation.

A previous study indicated that during a period starting several hours after the training session, processes used to encode spatial information became active (15). REM sleep is likely to be involved in the processing of memory. Historically, REM sleep deprivation impaired learning and memory from the Morris water maze $(15,39,40)$ and the radial arm maze task (16). In the present study we, aimed to extend these findings by comparing the effect of REM sleep deprivation upon memory in a different task (hexagonal maze). Using this apparatus allowed us to examine simultaneously the consequences of REM sleep deprivation on reference memory and cognitive ability. Although the characteristic of FF increased, while FT decreased, rats in the narrow platform group exhibited more errors and a lower level of CR. The findings indicated that following to a 96-h sleep deprivation, rats in the narrow platform group were more eager to exit the maze (compared to rats in the wide platform group), although they could not remember the exits they had previously used and ran to the doors in disorder or in turns. This finding suggested that all parameters should be considered (not just individually) when evaluating performances of rats in the hexagonal maze. The findings in this study were consistent with those of other authors (13), suggesting REM sleep deprivation induced memory impairments and a decline in the cognitive functioning of rats. Despite the fact that REM sleep deprivation increased the willingness of the animal to escape an uncomfortable environment, an adequate reference memory was not formed. Since rats were deprived of sleep and in particular of the REM stage, the animals exhibited increased aggression, as well as locomotor and exploratory activity, but impaired attention function, decreased emotionality and a greater sensitivity to environmental stimuli compared to the controls $(39,41)$, resulting in changes in FT and FF. Notably, the findings were not consistent with those of Sloan (42), suggesting that the animal's maze-learning ability was not consistently affected by the deprivation procedure. The discrepancy may be due to the different cognitive task (Sloan used the T maze to determine the effects of REM sleep deprivation). Hartmann and Stern (43) reported that after $96 \mathrm{~h}$ of REM sleep deprivation, the learning deficit was secondary to the depletion of central catecholamines. Furthermore, the impairments of learning may have occurred due to a delay in the transfer of information from the short- to the long-term memory, a function of the REM stage, as suggested by Smith (16).

In summary, the learning ability and memory of male rats of various age were investigated, based on their performance in a hexagonal maze. Rats of various age showed differences in memory and cognitive ability. Middle-aged male rats exhibited the highest level of ability compared to the young and old age groups. In addition, subsequent to REM sleep deprivation, rats in the narrow platform group showed more errors and a lower level of CR, as they did not form a good reference memory. Based on the preliminary validation, to a certain extent, the hexagonal maze procedure reflected the learning 
and memory abilities of rats. Additional studies are required to validate this finding.

\section{Acknowledgements}

This study was supported by the National Natural Science Foundation of China (no. 81073077).

\section{References}

1. McLean JH, Smith A, Rogers S, Clarke K, Darby-King A and Harley CW: A phosphodiesterase inhibitor, cilomilast, enhances cAMP activity to restore conditioned odor preference memory after serotonergic depletion in the neonate rat. Neurobiol Learn Mem 92: 63-69, 2009.

2. Meneses A and Perez-Garcia G: 5-HT1A receptors and memory. Neurosci Biobehav Rev 31: 705-727, 2007.

3. Hersi AI, Rowe W, Gaudreau P and Quirion R: Dopamine D1 receptor ligands modulate cognitive performance and hippocampal acetylcholine release in memory-impaired aged rats. Neuroscience 69: 1067-1074, 1995.

4. Kida Y, Tachibana H, Takeda M, Yoshikawa H and Okita T: Recognition memory for unfamiliar faces in Parkinson's disease: behavioral and electrophysiologic measures. Parkinsonism Relat Disord 13: 157-164, 2007.

5. Cipolli C,Neri M,De Vreese LP, Pinelli M, Rubichi S and Lalla M: The influence of depression on memory and metamemory in the elderly. Arch Gerontol Geriatr 23: 111-127, 1996.

6. Leplow B, Dierks Ch, Herrmann P, Pieper N, Annecke R and Ulm G: Remote memory in Parkinson's disease and senile dementia. Neuropsychologia 35: 547-557, 1997.

7. Ozdemir D, Tugyan K, Uysal N, Sonmez U, Sonmez A, Acikgoz O, et al: Protective effect of melatonin against head trauma-induced hippocampal damage and spatial memory deficits in immature rats. Neurosci Lett 385: 234-239, 2005.

8. Eppinger B, Herbert M and Kray J: We remember the good things: age differences in learning and memory. Neurobiol Learn Mem 93: 515-521, 2010

9. Mishra A and Goel RK: Age dependent learning and memory deficit in Pentylenetetrazol kindled mice. Eur J Pharmacol 674 315-320, 2012.

10. Fahle $\mathrm{M}$ and Daum I: Visual learning and memory as functions of age. Neuropsychologia 35: 1583-1589, 1997.

11. Maquet P: The role of sleep in learning and memory. Science 294: 1048-1052, 2001

12. Walker MP and Stickgold R: Sleep-dependent learning and memory consolidation. Neuron 44: 121-133, 2004.

13. Ratcliff R, Hans PA and Dongen V: Sleep deprivation affects multiple distinct cognitive processes. Psychon Bull Rev 16: 742-751, 2009.

14. Peigneux P, Laureys S, Delbeuck X and Maquet P: Sleeping brain, learning brain. The role of sleep for memory systems Neuroreport 12: A111-A124, 2001.

15. Smith C and Rose GM: Evidence for a paradoxical sleep window for place learning in the Morris water maze. Physiol Behav 59: 93-97, 1996.

16. Smith CT, Conway JM and Rose GM: Brief paradoxical sleep deprivation impairs reference, but not working, memory in the radial arm maze task. Neurobiol Learn Mem 69: 211-217, 1998

17. Zhang L, Guo XH and Zhao ZX: Effect of modafinil on the cognitive function of rats after rapid eye movement sleep deprivation and sleep recovery. J Shanghai Med 31: 175-178, 2008.

18. Morris R: Developments of a water-maze procedure for studying spatial learning in the rat. J Neurosci Methods 11: 47-60, 1984.

19. Kraemer PJ, Brown RW, Baldwin SA and Scheff SW: Validation of a single-day Morris water maze procedure used to assess cognitive deficits associated with brain damage. Brain Res Bull 39: 17-22, 1996.

20. Wolfer DP and Lipp HP: A new computer program for detailed off-line analysis of swimming navigation in the Morris water maze. J Neurosci Methods 41: 65-74, 1992.

21. Olton DS and Samuelson RJ: Remembrance of places passed: spatial memory in rats. J Exp Psychol 2: 97-116, 1976.
22. Hodges H, Allen Y, Sinden J, Mitchell SN, Arendt T, Lantos PL, and Gray JA: The effects of cholinergic drugs and cholinergic-rich foetal neural transplants on alcohol-induced deficits in radial maze performance in rats. Behav Brain Res 43: 7-28, 1991.

23. Levin ED and Christopher CN: Lobeline-induced learning improvement of rats in the radial-arm maze. Pharmacol Biochem Behav 76: 133-139, 2003.

24. Martinez JL Jr, Petty C and Messing RB: Regional brain uptake of 2-deoxy-D-glucose following training in a discriminated y-maze avoidance task. J Comp Physiol Psychol 96: 721-724, 1982.

25. Beninger RJ, Kühnemann S, Ingles JL, Jhamandas $\mathrm{K}$ and Boegman RJ: Mnemonic deficits in the double Y-maze are related to the effects of nucleus basalis injections of ibotenic and quisqualic acid on choline acetyltransferase in the rat amygdala. Brain Res Bull 35: 147-152, 1994.

26. Dean O, Bush AI, Berk M, Copolovd DL and Buuseand M: Glutathione depletion in the brain disrupts short-term spatial memory in the Y-maze in rats and mice. Behav Brain Res 198: 258-262, 2009.

27. Ingram DK, London ED, Reynolds MA, Waller SB and Goodrick CL: Differential effects of age on motor performance in two mouse strains. Neurobiol Aging 2: 221-227, 1981.

28. Shukitt-Hale B, Mouzakis G and Joseph JA: Psychomotor and spatial memory performance in aging male Fischer 344 rats. Exp Gerontol 33: 615-624, 1998

29. Kobayashi S, Kametani H, Ugawa Y and Osanai M: Age difference of response strategy in radial maze performance of Fischer-344 rats. Physiol Behav 2: 277-280, 1988.

30. Warren SG and Juraska JM: Sex differences and estropausal phase effects on water maze performance in aged rats. Neurobiol Learn Mem 74: 229-240, 2000.

31. Li HB, Matsumoto K. Tohda M, Yamamoto $M$ and Watanabe $\mathrm{H}$ : NMDA-but not AMPA-receptor antagonists augment scopolamine-induced spatial cognitive deficit of rats in a radial maze task. Brain Res 725: 268-271, 1996.

32. Fibiger HC: Cholinergic mechanisms in learning, memory and dementia: a review of recent evidence. Trends Neurosci 14: 220-223, 1991

33. Baxter MG, Frick KM, Price DL, Brecklerb SJ, Markowskab AL and Gorman LK: Presynaptic markers of cholinergic function in the rat brain: relationship with age and cognitive status. Neuroscience 89: 771-780, 1999.

34. Machado RB, Hipolide DC, Benedito-Silva AA and Tufik S: Sleep deprivation induced by the modified multiple platform technique: quantification of sleep loss and recovery. Brain Res 1004: 45-51, 2004.

35. Jouvet D, Vimont P and Delorme F: Study of selective deprivation of the paradoxic phase of sleep in the cat. J Physiol (Paris) 56: 756-759, 1964 (In French).

36. Cohen HB and Dement WC: Sleep: changes in threshold to electroconvulsive shock in rats after deprivation of paradoxical phase. Science 150: 1318-1319, 1965

37. Van Hulzen ZJM and Coenen AML: Paradoxical sleep deprivation and locomotor activity in rats. Physiol Behav 27: 741-744, 1981.

38. Suchecki D and Tufik S: Social stability attenuates the stress in the modified multiple platform method for paradoxical sleep deprivation in the rat. Physiol Behav 68: 309-316, 2000.

39. Youngblood BD, Zhou J, Smagin GN, Ryana DH and Harris RBS: Sleep deprivation by the 'flower pot' technique and spatial reference memory. Physiol Behav 61: 249-256, 1997.

40. Yang RH, Hu SJ, Wang Y, Zhang WB, Luo WJ and Chen JY: Paradoxical sleep deprivation impairs spatial learning and affects membrane excitability and mitochondrial protein in the hippocampus. Brain Res 1230: 224-232, 2008.

41. Godoi FR, Oliveira MG and Tufik S: Effects of paradoxical sleep deprivation on the performance of rats in a model of visual attention. Behav Brain Res 165: 138-145, 2005.

42. Sloan MA: The effects of deprivation of rapid eye movement (REM) sleep on maze learning and aggression in the albino rat. J Psychiatr Res 9: 101-111, 1972.

43. Hartmann E and Stern WC: Desynchronized sleep deprivation: learning deficit and its reversal by increased catecholamines. Physiol Behav 8: 585-587, 1972. 